\title{
The factors limiting the diagnostic accuracy of myocardial perfusion cardiac magnetic resonance imaging: coronary flow reserve and amount of myocardial scar
}

\author{
Masaki Ishida ${ }^{1 *}$, Shingo Kato ${ }^{1}$, Nanaka Ishida ${ }^{1}$, Motonori Nagata' ${ }^{1}$, Kakuya Kitagawa' ${ }^{1}$ Hiroshi Nakajima², \\ Shiro Nakamori ${ }^{2}$, Hajime Sakuma ${ }^{1}$
}

From 15th Annual SCMR Scientific Sessions

Orlando, FL, USA. 2-5 February 2012

\section{Background}

Perfusion cardiac magnetic resonance (CMR) imaging has emerged as an important clinical tool for the accurate detection of myocardial ischemia caused by significant coronary artery disease (CAD), whereas most previous studies demonstrated the diagnostic accuracy of perfusion CMR in a highly selected patient population such as those without previous myocardial infarction or lower ejection fraction (EF) etc. In the real clinical practice, however, we may encounter the patients with multiple factors affecting the accurate CMR myocardial perfusion assessment. The aim of this study was to identify the factors reducing the sensitivity of perfusion CMR for predicting significant CAD determined by the coronary angiography (CAG).

\section{Methods}

181 patients with known or suspected CAD underwent both CMR imaging and CAG. Patients who had previously undergone coronary artery bypass graft were excluded. CMR imaging was performed at either $1.5 \mathrm{~T}$ or 3 system. Perfusion CMR images were acquired at rest and during ATP stress with Gadolinium (Gd) dose of $0.05(0.03) \mathrm{mmol} / \mathrm{kg}$ at $1.5 \mathrm{~T}(3 \mathrm{~T})$. Coronary sinus flow measurement was performed at rest and during stress using phase contrast cine MR imaging to calculate coronary flow reserve (CFR). Short axis cine stack was obtained to calculate LV volume and function. Late gadolinium enhancement (LGE) imaging was performed

'Radiology, Mie University Hospital, Tsu, Japan

Full list of author information is available at the end of the article using cumulative Gd dose of $0.15 \mathrm{mmol} / \mathrm{kg}$. Presence or absence of ischemia in individual coronary territories was visually determined on perfusion CMR images. Percentage myocardium affected by scar in the territories (\%LGE) was then calculated. Coronary artery stenosis $\geq 70 \%$ was considered significant. Candidate variables to be included in multivariate analysis were: LV end-diastolic volume, cardiac output, EF, CFR and \%LGE.

\section{Results}

Of 543 coronary territories, 266 corresponded to significant CAD. Of these, 61 (22.9\%) were judged as absence of ischemia (false negative). Per-territory analysis demonstrated the sensitivity of perfusion CMR for predicting significant CAD was $77.1 \%$ whilst overall perpatient analysis indicated a sensitivity of $85.5 \%$. In multiple logistic regression analysis, the independent factors to have a significant relationship with the false negative were CFR (Odds ratio, 0.59; 95\% confidence interval (CI), 0.44-0.80) and \%LGE (1.03; 1.02-1.04) (table 1). Using a threshold of CFR $=2$ and $\% \mathrm{LGE}=25 \%$, smaller CFR and larger \%LGE groups had substantially lower sensitivity (table 2).

\section{Conclusions}

The current results indicate that reduced CFR and increased myocardial scar are associated with reduced sensitivity in detecting myocardial ischemia on stress CMR perfusion images.

\section{Funding}

Nothing to disclose. 
Table 1 Results of the multiple logistic regression analysis

\begin{tabular}{ccccc}
\hline & Significance probability $(\mathrm{p})$ & Odds ratio & \multicolumn{2}{c}{$95 \% \mathrm{Cl}$} \\
\cline { 5 - 6 } \cline { 4 - 5 } & & & lower & upper \\
\hline CFR & 0.001 & 0.591 & 0.439 & 0.795 \\
\hline \%LGE & 0.001 & 1.025 & 1.011 & 1.04 \\
\hline
\end{tabular}

Table 2 Diagnostic performance of perfusion CMR imaging

\begin{tabular}{|c|c|c|c|c|c|c|c|c|}
\hline & & & $\mathrm{n}$ & Sensitivity & $p^{*}$ & PPV & NPV & Specificity \\
\hline \multirow[t]{3}{*}{$\begin{array}{c}\text { Per Patient } \\
\text { Analysis }\end{array}$} & & & 181 & 85.5 & - & 95.4 & 58.8 & 83.3 \\
\hline & & all & 543 & 77.1 & - & 89.1 & 80.5 & 91.0 \\
\hline & CFR & $\leqq 2$ & 153 & 70.8 & 0.056 & 91.3 & 58.9 & 86.0 \\
\hline \multirow{3}{*}{$\begin{array}{c}\text { Per Territory } \\
\text { Analysis }\end{array}$} & & $2<$ & 390 & 81.0 & & 88.0 & 87.1 & 92.1 \\
\hline & $\begin{array}{c}\% \\
L G E\end{array}$ & $\leqq 25 \%$ & 484 & 80.5 & 0.001 & 89.4 & 84.6 & 91.8 \\
\hline & & $\begin{array}{c}25 \% \\
<\end{array}$ & 59 & 56.1 & & 88.5 & 45.5 & 83.3 \\
\hline
\end{tabular}

*: Chi-square test

Author details

${ }^{1}$ Radiology, Mie University Hospital, Tsu, Japan. ${ }^{2}$ Cardiology, Mie University

Hospital, Tsu, Japan.

Published: 1 February 2012

doi:10.1186/1532-429X-14-S1-088

Cite this article as: Ishida et al.: The factors limiting the diagnostic accuracy of myocardial perfusion cardiac magnetic resonance imaging: coronary flow reserve and amount of myocardial scar. Journal of Cardiovascular Magnetic Resonance 2012 14(Suppl 1):O88.

Submit your next manuscript to BioMed Central and take full advantage of:

- Convenient online submission

- Thorough peer review

- No space constraints or color figure charges

- Immediate publication on acceptance

- Inclusion in PubMed, CAS, Scopus and Google Scholar

- Research which is freely available for redistribution

Submit your manuscript at www.biomedcentral.com/submit 